\title{
Perilaku self-management dengan kejadian ulkus diabetikum Pada pasien diabetes mellitus tipe 2
}

\author{
Eka Yudha Chrisanto ${ }^{1 *}$, Agustama $^{2}$
}

1Program Studi Diploma III Keperawatan Universitas Malahayati. *Email: yudhachrisanto88@gmail.com

${ }^{2}$ Rumah Sakit Natar Medika Kabupaten Lampung Selatan

\section{Abstract \\ Self-management behaviour and diabetic foot ulcer occurrence among patient with type 2 diabetes mellitus}

Background: Diabetes mellitus is one of the silent killers. Indonesia is a country with the 4th largest number of people with diabetes mellitus after China, India, and the United States. In Indonesia people with diabetes mellitus increased from 8.4 million in 2000 to 21.3 million in 2030.

Purpose: To determine the self-management behaviour and diabetic foot ulcer occurrence among patient with type 2 diabetes mellitus.

Method: A quantitative research type, with cross sectional analytic and analytical research designs. The population of all people with diabetes mellitus as many as 432 people and a sample of 38 people with a total sampling technique. Data collection using questionnaire sheets and statistical tests used were Chi-Square statistical tests.

Results: The frequency distribution of the incidence of diabetic ulcers in patients with type 2 diabetes mellitus, with the category of diabetic ulcers occurring as many as 14 respondents (36.8\%). Diabetes diet adherence in patients with diabetes mellitus, with the category of non-compliance with 16 respondents (42.1\%). Monitoring blood sugar levels in patients with type 2 diabetes mellitus, with non-routine categories of 15 respondents $(39.5 \%)$. Physical activity in patients with type 2 diabetes mellitus, with a less good category of 19 respondents $(50 \%)$.

Conclusion: There is a relationship between blood sugar and diabetic ulcer diabetes in type 2 diabetes mellitus patients. There is a relationship between diabetes diet and diabetic ulcer diabetes in type 2 diabetes mellitus patients. There is a relationship between physical activity and the incidence of diabetic ulcers in patients with type 2 diabetes mellitus. It is expected that DM patients can routinely carry out physical and routine activities with high salt levels) in health care facilities and carry out a diabetes diet in accordance with the rules proposed by nutritionists.

\section{Keywords: Self-management; Behaviour; Diabetic foot ulcer; Occurrence; Patient; Type 2 diabetes mellitus}

Pendahuluan: Diabetes melitus salah satu the silent killer. Indonesia merupakan negara dengan jumlah penderita diabetes melitus ke-4 terbanyak setelah Cina, India, dan Amerika Serikat. di Indonesia penyandang diabetes melitus mengalami kenaikan dari 8,4 juta pada tahun 2000 menjadi 21,3 juta pada tahun 2030.

Tujuan: Diketahui hubungan perilaku self-management dengan kejadian ulkus diabetikum pada pasien diabetes mellitus tipe 2

Metode: Jenis penelitian kuantitatif, dengan rancangan penelitian analitik dan pendekatan cross sectional. Populasi seluruh seluruh penderita diabetes melitus sebanyak 432 orang dan sampel sebanyak 38 orang dengan teknik total Sampling. Pengumpulan data menggunakan lembar kuesioner dan Uji statistik yang digunakan adalah uji statistik Chi-Square.

Hasil: Distribusi frekuensi kejadian ulkus diabetikum pada penderita diabetes melitus tipe 2, dengan kategori terjadi ulkus diabetikum sebanyak 14 responden $(36,8 \%)$. Kepatuhan diet diabetes pada pasien diabetes melitus, dengan kategori tidak patuh sebanyak 16 responden $(42,1 \%)$. Pemantauan kadar gula darah pada pasien diabetes melitus tipe 2, dengan kategori tidak rutin sebanyak 15 responden (39,5\%). Aktivitas fisik pada pasien diabetes melitus tipe 2, dengan kategori kurang baik sebanyak 19 responden $(50 \%)$. 
Perilaku Self-Management dengan kejadian ulkus diabetikum pada pasien diabetes mellitus tipe 2

Simpulan: Ada hubungan pemantauan kadar gula darah dengan kejadian ulkus diabetikum pada pasien diabetes melitus tipe 2. Ada hubungan kepatuhan diet diabetes dengan kejadian ulkus diabetikum pada pasien diabetes melitus tipe 2. Ada hubungan aktivitas fisik dengan kejadian ulkus diabetikum pada pasien diabetes melitus tipe 2. Diharapkan pasien DM agar rutin melakukan aktivitas fisik serta rutin mengontrol kadar gula darah pada fasilitas pelayanan kesehatan Serta menjalankan diet diabetes sesuai dengan aturan yang disarankan ahli gizi.

\section{Kata Kunci: Kadar Gula Darah; Diet; Aktivitas; Ulkus Diabetikum}

\section{PENDAHULUAN}

Penyakit tidak menular (PTM) merupakan penyakit kronis yang tidak ditularkan dari orang ke orang. PTM diantaranya adalah penyakit jantung, stroke, kanker, diabetes, dan Penyakit Paru Obstruktif Kronis (PPOK). PTM merupakan hampir $70 \%$ penyebab kematian di dunia. Sementara itu, PTM menunjukkan adanya kecenderungan semakin meningkat dari waktu ke waktu. Adapun faktor risiko antara terjadinya PTM adalah obesitas, tekanan darah tinggi, gula darah tinggi, dan kolesterol tinggi (Arisman, 2011). Prinsip upaya pencegahan tetap lebih baik dari pengobatan. Upaya pencegahan penyakit tidak menular lebih ditujukan kepada faktor risiko yang telah diidentifikasi (Kementerian Kesehatan Republik Indonesia, 2017).

Pada tahun 2016 menunjukkan bahwa sekitar 150 juta orang menderita DM di seluruh dunia, dan jumlah ini akan meningkat dua kali lipat pada tahun 2025. Kenaikan ini akan terjadi di negara-negara berkembang yang disebabkan oleh pertumbuhan populasi, penuaan, diet tidak sehat, obesitas dan gaya hidup tidak sehat seperti kurangnya aktivitas fisik (olahraga), mengkonsumsi makanan atau minuman tinggi gula dan mengkonsumsi alkohol (American Diabetes Association, 2016; Wahyuni, Hasneli, \& Ernawaty, 2018).

Diabetes melitus salah satu the silent killer dan merupakan penyakit yang akan memicu krisis kesehatan terbesar pada abat ke-21. Indonesia merupakan negara dengan jumlah penderita diabetes melitus ke-4 terbanyak setelah Cina, India, dan Amerika Serikat. Perkiraan untuk Indonesia berdasarkan prediksi WHO dalam (Perkumpulan Endokrinologi Indonesia, 2015). Penyandang diabetes melitus mengalami kenaikan dari 8,4 juta pada tahun 2000 menjadi 21,3 juta pada tahun 2030 (Kementerian Kesehatan Republik Indonesia, 2017).

Sementara itu di Dinas Kesehatan Provinsi Lampung tercatat bahwa pada tahun 2017 jumlah penderita diabetes melitus mengalami peningkatan $12 \%$ dari periode sebelumnya yaitu sebanyak 38.923 kasus. Sedangkan di Kabupaten Lampung Selatan Tahun 2018 kasus diabetes melitus menempati urutan ketiga di Provinsi Lampung, tertinggi di Kabupaten Lampung Tengah, dan terendah di Kabupaten Pesawaran. Kasus diabetes melitus pada tahun 2016 sebanyak $29,9 \%$, tahun 2017 sebanyak $32,6 \%$ dan meningkat pada tahun 2018 menjadi $34,9 \%$.

Prevalansi diabetes melitus di RS Natar Medika Kabupaten Lampung Selatan dari laporan terakhir prevalensi jumlah kunjungan rawat jalan penderita diabetes mellitus pada tahun 2018 jumlah kunjungan rawat jalan pasien diabetes mellitus kasus baru sebanyak 853 sedangkan sampai Februari 2019 kunjungan pasien diabetes melitus tipe 2 sebanyak 152 pasien, pada tahun 2018 sebanyak 32,8\% kasus diabetes mellitus tipe 2 .

Komplikasi diabetes melitus dapat terjadi karena kadar gula darah yang buruk. Agar kadar gula darah tetap terkendali maka perlu dilakukan perawatan dan pengelolaan diabetes. Strategi dalam melakukan perawatan dan pengelolaan diabetes untuk mencapai kadar gula darah yang memuaskan diantaranya yaitu melakukan edukasi pengobatan, terapi nutrisi medis dan aktivitas yang rutin (Rahayu, Saraswati, \& Setyawan, 2018). . Hal yang tidak kalah penting dalam pengendalian terhadap diabetes melitus yakni memeriksa kadar gula darah secara berkala. Pengendalian kadar gula darah bagi penderita diabetes merupakan hal yang penting karena dengan pengendalian gula darah yang baik maka komplikasi akibat diabetes dapat dicegah. Kaki diabetik dengan ulkus merupakan komplikasi diabetes yang sering terjadi. Ulkus kaki diabetik adalah luka kronik pada daerah di bawah pergelangan kaki, yang meningkatkan morbiditas, mortalitas, dan mengurangi kualitas hidup pasien (Fathmi, 2012).

Faktor risiko diabtes melitus tipe 2 dibedakan menjadi faktor yang dapat dimodifikasi dan faktor

Eka Yudha Chrisanto"* Program Studi Diploma III Keperawatan Universitas Malahayati.

*Email: yudhachrisanto88@gmail.com

Agustama ${ }^{2}$ Rumah Sakit Natar Medika Kabupaten Lampung Selatan 
Perilaku Self-Management dengan kejadian ulkus diabetikum pada pasien diabetes mellitus tipe 2

yang tidak dapat dimodifikasi. Usaha pencegahan dilakukan dengan mengurangi risiko yang dapat dimodifikasi. Pencegahan diabetes tipe 2 pada orang-orang berisiko prinsipnya adalah dengan mengubah pola makan, gaya hidup dan menjalankan latihan fisik yang rutin seperti olah raga dan penurunan berat badan (Kartika, 2017).

Hasil penelitian sebelumnya menunjukkan bahwa pasien DM dengan gula darah yang tidak terkontrol adalah $20(66,7 \%)$. Pasien DM yang melakukannya tidak mengalami gangren sebanyak 18 orang $(60 \%)$. Hasil uji memiliki hubungan antara gula darah hubungan dengan kejadian gangren pada pasien DM $(O R=11.000$, nilai $p 0,024)$ (Wahyuni, Hasneli, \& Ernawaty, 2018).

Hasil pre survei di RS Natar Medika Kabupaten Lampung Selatan terhadap 10 orang pasien diabetes melitus mengalami kenaikan kadar gula darah pada saat pemeriksaan GDS rata-rata $\geq$ $200 \mathrm{mg} / \mathrm{dL}$. Pada saat dilakukan pemeriksaan diketahi bahwa $60 \%$ diantaranya mengatakan tidak pernah beraktivitas fisik seperti berolahraga serta pasien tidak melakukan anjuran dari petugas kesehatan dalam diet diabetes melitus dan $50 \%$ mengalami ulkus diabetikum.

\section{METODE PENELITIAN}

Jenis penelitian kuantitatif dengan rancangan analitik dan pendekatan cross sectional, sudah lulus kelaikan etik dari Komisi Etik Penelitian Kesehatan Universitas Malahayati dengan nomor surat keterangan kelaikan etik 323/EC/KEPUNMAL///2019 pada tanggal 20 Mei 2019. Penelitian dilaksanakan di RS Natar Medika pada Juli s/d Agustus tahun 2019. Instrument tentang kepatuhan diet diabetes melitus terdiri dari 10 pertanyaan meliputi frekuensi dalam mengkonsumsi makanan yang disarankan dan tidak disarankan. Kepatuhan melakukan aktivitas fisik atau latihan terdiri dari 6 item pertanyaan meliputi jenis,durasi dan frekuensi. Responden dikatakan Rutin jika melakukan olah raga atau pekerjaan yang membutuhkan aktifitas ringan, sedang dan teratur dengan frekuensi 3-4 kali/minggu total durasi 90 menit per menit. Instrumen pemantauan kadar glukosa darah terdiri dari tiga pertanyaan. Responden dikatakan rutin jika dilakukan teratur dengan frekuensi 1-2 kali setiap 4 minggu atau setiap kunjungan berobat. Responden dikatakn tidak teratur jika pemeriksaan tidak teratur dan frekuensi kurang dari 1 kali dalam 4 minggu.Perawatan kaki terdiri dari 14 pertanyaan mengenai aktifitas fisik yang dilakukan dalam melakukan aktifitas fisik dan pencegahan luka pada kaki. Sampel yang diambil sebanyak 3jenjelama8 pasien. Pengambilan sampel menggunakan teknik total sampling. Analisis hubungan pemantauan kadar gula darah, kepatuhan diet diabetes dan aktivitas fisik dengan kejadian ulkus diabetikum dianalisis menggunakan uji statistik Chi-Square. Kriteria inklusi penelitian ini yaitu pasien DM yang telah mendapatkan edukasi perawatan DM, pasien DM dengan atau tanpa ulkus. dapat membaca dan menulis, bersedia menjadi responden dan kooperatif. Pengumpulan data dengan data primer dan data sekunder. Data primer diperoleh melalui wawancara langsung. Sementara data sekunder meliputi data rekam medik Rumah sakit. Setelah data terkumpul selanjutnya dilakukan pengolahan data.

Eka Yudha Chrisanto"* Program Studi Diploma IIl Keperawatan Universitas Malahayati.

*Email: yudhachrisanto88@gmail.com

Agustama $^{2}$ Rumah Sakit Natar Medika Kabupaten Lampung Selatan 
HASIL

Tabel. 1. Karakteristik Demografi Responden $\mathrm{N}=38$

\begin{tabular}{|c|c|c|c|c|}
\hline \multicolumn{2}{|l|}{ Demografi } & $\mathrm{n}$ & $\%$ & $M(S D)$ \\
\hline \multicolumn{2}{|l|}{ Usia (Tahun)(Rentang: 36-69) } & 38 & & $52.39 \pm 7.387$ \\
\hline \multicolumn{2}{|c|}{ Lamanya sakit (Tahun)(Rentang: 3-10) } & 38 & & $5.50 \pm 1.983$ \\
\hline \multirow[t]{2}{*}{ Jenis Kelamin } & Laki-Laki & 22 & 57.90 & \\
\hline & Perempuan & 16 & 42.10 & \\
\hline \multirow[t]{4}{*}{ Pendidikan } & SD & 2 & 5.26 & \\
\hline & SMP & 19 & 50 & \\
\hline & SMA & 13 & 34.22 & \\
\hline & Perguruan Tinggi & 4 & 10.52 & \\
\hline \multirow[t]{2}{*}{ Pekerjaan } & Tidak Bekerja & 16 & 42.1 & \\
\hline & Bekerja & 22 & 57.9 & \\
\hline \multirow[t]{2}{*}{ Kejadian Ulkus Diabetikum } & Terjadi Ulkus Diabetikum & 14 & 36.8 & \\
\hline & Tidak Ada Ulkus Diabetikum & 24 & 63.2 & \\
\hline \multirow[t]{2}{*}{ Pemantauan Kadar Gula Darah } & Tidak Rutin & 15 & 39.5 & \\
\hline & Rutin & 23 & 60.5 & \\
\hline \multirow[t]{2}{*}{ Kepatuhan Diet Diabetes } & Tidak Patuh & 16 & 42.1 & \\
\hline & Patuh & 22 & 57.9 & \\
\hline \multirow[t]{2}{*}{ Aktivitas Fisik } & Buruk & 19 & 50.0 & \\
\hline & Baik & 19 & 50.0 & \\
\hline
\end{tabular}

Berdasarkan tabel 1. diketahui bahwa responden berusia antara 36 tahun sampai dengan 69 tahun dengan mean sebesar 52.39 dan standar deviasi 7.387. Tahun lamanya sakit antara 3 tahun sampai 10 tahun dengan mean sebesar 5.50 dan standar deviasi 1.983. Karakteristik pendidikan pada penderita diabetes melitus tipe 2 sebagian besar adalah SMP sebanyak 19 responden (50\%). Jenis kelamin penderita sebagian besar adalah lakilaki sebanyak 22 responden $(57,90 \%)$. Karakteristik pekerjaan pada penderita diabetes melitus tipe 2 sebagian besar adalah Bekerja sebanyak 22 responden (57.9\%). Diketahui bahwa kejadian ulkus diabetikum pada penderita diabetes melitus tipe 2 dengan kategori tidak ada ulkus diabetikum sebanyak 24 responden $(63,2 \%)$ sedangkan kategori terjadi ulkus diabetikum sebanyak 14 responden (36,8\%). Diketahui bahwa pemantauan kadar gula darah pada pasien diabetes melitus dengan kategori rutin sebanyak 23 responden $(60,5 \%)$ sedangkan kategori tidak rutin sebanyak 15 responden (39,5\%). Diketahui bahwa kepatuhan diet diabetes pada pasien diabetes melitus dengan kategori tidak patuh sebanyak 16 responden $(42,1 \%)$ sedangkan kategori patuh sebanyak 22 responden $(57,9 \%)$. Diketahui bahwa aktivitas fisik pada pasien diabetes melitus dengan kategori buruk sebanyak 19 responden (50\%) sedangkan kategori baik sebanyak 19 responden (50\%).

Eka Yudha Chrisanto* Program Studi Diploma IIl Keperawatan Universitas Malahayati.

*Email: yudhachrisanto88@gmail.com

Agustama ${ }^{2}$ Rumah Sakit Natar Medika Kabupaten Lampung Selatan 
Perilaku Self-Management dengan kejadian ulkus diabetikum pada pasien diabetes mellitus tipe 2

Tabel 2. Hubungan Variabel Dengan Kejadian Ulkus Diabetikum N=38

\begin{tabular}{|c|c|c|c|c|c|c|c|c|}
\hline \multirow[t]{3}{*}{ Variabel } & \multicolumn{4}{|c|}{ Kejadian ulkus diabetikum } & \multirow{2}{*}{\multicolumn{2}{|c|}{ Total }} & \multirow{3}{*}{$p$-value } & \multirow{3}{*}{$\begin{array}{c}\text { OR } \\
(95 \% \mathrm{Cl})\end{array}$} \\
\hline & \multicolumn{2}{|c|}{ Terjadi ulkus } & \multicolumn{2}{|c|}{ Tidak ada ulkus } & & & & \\
\hline & $n$ & $\%$ & $\mathrm{n}$ & $\%$ & $\mathbf{N}$ & $\%$ & & \\
\hline \multicolumn{9}{|c|}{ Pemantauan kadar gula darah } \\
\hline Tidak Rutin & 10 & 26.3 & 5 & 13.2 & 15 & 39.5 & \multirow[t]{2}{*}{0,006} & 9,500 \\
\hline Rutin & 4 & 10.5 & 19 & 50.0 & 23 & 60.5 & & $(2,075-43,502)$ \\
\hline \multicolumn{9}{|c|}{ Kepatuhan Diet Diabetes } \\
\hline Tidak Patuh & 11 & 28.9 & 5 & 13.2 & 16 & 42.1 & \multirow{2}{*}{0,002} & \multirow{2}{*}{$\begin{array}{c}13,933 \\
(2,778-69,881)\end{array}$} \\
\hline Patuh & 3 & 7.9 & 19 & 50.0 & 22 & 57.9 & & \\
\hline \multicolumn{9}{|c|}{ Aktivitas Fisik } \\
\hline Buruk & 12 & 31.6 & 7 & 18.4 & 19 & 50.0 & \multirow[t]{2}{*}{0,002} & \multirow{2}{*}{$\begin{array}{c}14,571 \\
(2,566-82,732)\end{array}$} \\
\hline Baik & 2 & 5.3 & 17 & 44.7 & 19 & 50.0 & & \\
\hline
\end{tabular}

\section{Berkaitan Dengan Pemantauan kadar gula darah}

Berdasarkan tabel 2. diketahui bahwa dari 15 responden dengan kategori pemantauan kadar gula darah tidak rutin dan terjadi ulkus diabetikum sebanyak 10 responden $(26.3 \%)$, dan tidak ada ulkus diabetikum sebanyak 5 responden (13.2\%). Sedangkan dari 23 responden dengan kategori pemantauan kadar gula darah rutin dan terjadi ulkus diabetikum sebanyak 4 responden $(10.5 \%)$ dan tidak ada ulkus diabetikum sebanyak 19 responden $(50.0 \%)$. Hasil uji statistik $p$ value $=$ 0,006 lebih kecil dari nilai alpha $(\alpha=0,05)$, sehingga ada hubungan pemantauan kadar gula darah dengan kejadian ulkus diabetikum. Hasil analisis diperoleh nilai OR: 9,500 atau dapat dikatakan pemantauan kadar gula darah yang tidak rutin berisiko 9,500 kali lebih besar terjadinya ulkus diabetikum pada pasien diabetes melitus tipe 2 dibandingkan dengan pemantauan kadar gula darah yang rutin.

\section{Berkaitan Dengan Kepatuhan Diet Diabetes}

Berdasarkan tabel 2. diketahui bahwa dari 16 responden dengan kategori kepatuhan diet diabetes tidak patuh dan terjadi ulkus diabetikum sebanyak 11 responden (28.9\%), dan tidak ada ulkus diabetikum sebanyak 5 responden (13.2\%). Sedangkan dari 22 responden dengan kategori kepatuhan diet diabetes kategori patuh dan terjadi ulkus diabetikum sebanyak 3 responden $(7.9 \%)$ dan tidak ada ulkus diabetikum sebanyak 19 responden $(50.0 \%)$. Hasil uji statistik $p$ value $=$ 0,002 lebih kecil dari nilai alpha $(\alpha=0,05)$, sehingga ada hubungan kepatuhan diet diabetes dengan kejadian ulkus diabetikum. Hasil analisis diperoleh nilai OR: 13,933 atau dapat dikatakan kepatuhan diet diabetes yang tidak patuh berisiko 13,933 kali lebih besar terjadinya ulkus diabetikum pada pasien diabetes melitus tipe 2 dibandingkan dengan kepatuhan diet diabetes dengan kategori patuh.

\section{Berkaitan Dengan Aktivitas Fisik}

Berdasarkan tabel 2. diketahui bahwa dari 19 responden dengan kategori aktivitas fisik buruk dan terjadi ulkus diabetikum sebanyak 12 responden $(31.6 \%)$, dan tidak ada ulkus diabetikum sebanyak 7 responden (18.4\%). Sedangkan dari 19 responden dengan kategori aktivitas fisik baik dan terjadi ulkus diabetikum sebanyak 2 responden (5.3\%) dan tidak ada ulkus diabetikum sebanyak 17 responden (44.7\%). Hasil uji statistik $p$ value $=0,002$ lebih kecil dari nilai alpha $(\alpha=0,05)$, sehingga ada hubungan aktivitas fisik dengan kejadian ulkus diabetikum. Hasil analisis diperoleh nilai OR: 14,571 atau dapat dikatakan aktivitas fisik yang kurang baik berisiko 14,571 kali lebih besar terjadinya ulkus diabetikum pada pasien diabetes melitus tipe 2 dibandingkan dengan aktivitas fisik yang baik.

\footnotetext{
Eka Yudha Chrisanto* Program Studi Diploma IIl Keperawatan Universitas Malahayati.

*Email: yudhachrisanto88@gmail.com

Agustama ${ }^{2}$ Rumah Sakit Natar Medika Kabupaten Lampung Selatan
} 


\section{PEMBAHASAN}

\section{Kejadian Ulkus Diabetikum}

Berdasarkan hasil dari pengumpulan data diketahui bahwa kejadian ulkus diabetikum dengan kategori terjadi ulkus diabetikum sebanyak 14 responden (36.8\%) sedangkan kategori tidak terjadi ulkus diabetikum sebanyak 24 responden $(63.2 \%)$.

Ulkus diabetikum salah satu bentuk komplikasi kronik diabetes melitus berupa luka terbuka pada permukaan kulit yang dapat disertai adanya kematian jaringan setempat (Lingga, 2012). Ulkus diabetikum luka terbuka pada permukaan kulit karena adanya komplikasi makroangiopati sehingga terjadi vaskuler insusifiensi dan neuropati, yang lebih lanjut terdapat luka pada penderita yang sering tidak dirasakan dan dapat berkembang menjadi infeksi disebabkan oleh bakteri aerob maupun anaerob (Yunus, 2015).

Hasil penelitian sebelumnya menunjukkan bahwa pasien DM dengan gula darah yang tidak terkontrol adalah $20(66,7 \%)$. Pasien DM yang melakukannya tidak mengalami gangren sebanyak 18 orang $(60 \%)$. Hasil uji memiliki hubungan antara gula darah hubungan dengan kejadian gangren pada pasien DM $(\mathrm{OR}=11.000$, nilai $\mathrm{p} 0,024)$ (Wahyuni, Hasneli, \& Ernawaty, 2018).

Menurut pendapat peneliti bahwa ulkus diabetikum merupakan luka terbuka pada permukaan kulit karena adanya komplikasi makroangiopati. Glukosa darah yang tidak terkendali akan menyebabkan penebalan pembuluh darah besar dan kapiler, sehingga aliran darah jaringan tepi kekaki terganggu dan nekrosis yang mengakibatkan ulkus diabetikum.

\section{Pemantauan Kadar Gula Darah}

Berdasarkan hasil dari pengumpulan data diketahui bahwa pemantauan kadar gula darah dengan kategori rutin sebanyak 23 responden $(60,5 \%)$ sedangkan kategori tidak rutin sebanyak 15 responden $(39,5 \%)$.

Intoleransi glukosa merupakan salah satu manifestasi sindrom metabolik yang dapat menjadi awal suatu diabetes melitus. Glukosa darah puasa merupakan salah satu cara untuk mengidentifikasi diabetes melitus pada seseorang (Ranti, Rumagit, \& Montol, 2013).. Pada penyakit ini, gula tidak siap untuk ditransfer ke dalam sel, sehingga terjadi hiperglikemi sebagai hasil bahwa glukosa tetap berada di dalam pembuluh darah (Setiati, Alwi,
Sudoyo, Simadibrata, Setiyohadi, \& Syam, 2014). Pasien yang tidak teratur melakukan kontrol kadar gula darah puasa dan kontrol kadar gula postprandial sebesar $54.4 \%$ (Rachmawati, \& Kusumaningrum, 2017).

Berdasarkan hal tersebut peneliti berpendapat bahwa kontrol kadar gula darah dikatakan teratur apabila dilakukan berkala yang meliputi pemeriksaan kadar gula puasa dan kadar gula darah 2 jam setelah makan atau hanya teratur melakukan pemeriksaan $\mathrm{HbA} 1 \mathrm{c}$ saja. Pemahaman pasien akan kondisinya sangat penting karena tingkat glukosa darah terus berubah. Seorang pasien harus memiliki pengetahuan yang cukup tentang penyakitnya sehingga mampu menjaga gula darah dalam batasan normal sehingga dapat mencegah terjadinya komplikasi diabetes. Beberapa hal yang dapat membantu pasien untuk menghindari masalah komplikasi tersebut adalah pendidikan, dukungan diet, pola hidup sehat dan pemantauan glukosa darah secara ketat

\section{Kepatuhan Diet Diabetes}

Berdasarkan hasil dari pengumpulan data diketahui bahwa kepatuhan diet diabetes dengan kategori tidak patuh sebanyak 16 responden $(42,1 \%)$ sedangkan kategori patuh sebanyak 22 responden $(57,9 \%)$.

Hal ini sesuai dengan teori bahwa gaya hidup adalah perilaku seseorang yang ditujukkan dalam aktivitas sehari-hari (Notoatmodjo, 2014). Makanan cepat saji (junk food), kurangnya berolahraga dan minum-minuman yang bersoda merupakan faktor pemicu terjadinya diabetes melitus tipe 2 (Kartika, 2017). Faktor risiko diabtes melitus tipe 2 dibedakan menjadi faktor yang dapat dimodifikasi dan faktor yang tidak dapat dimodifikasi. Usaha pencegahan dilakukan dengan mengurangi risiko yang dapat dimodifikasi. Pencegahan diabetes tipe 2 pada orang-orang berisiko prinsipnya adalah dengan mengubah pola makan, gaya hidup dan menjalankan latihan fisik yang rutin seperti olah raga dan penurunan berat badan (Aspiani, 2014).

Sejalan dengan penelitian sebelumnya, diketahui bahwa sebagian besar yang tidak diet sebanyak 16 orang $(94,1 \%)$ dan yang menjalankan diet sebanyak 1 orang $(5,9 \%)$ (Suryani, \& Septiana, 2016).

Berdasarkan hal tersebut peneliti berpendapat bahwa pola makan yang keliru menjadi salah satu faktor yang memicu munculnya penyakit diabetes

Eka Yudha Chrisanto* Program Studi Diploma IIl Keperawatan Universitas Malahayati.

*Email: yudhachrisanto88@gmail.com

Agustama ${ }^{2}$ Rumah Sakit Natar Medika Kabupaten Lampung Selatan 
melitus. Diantaranya mengkonsumsi makanan yang terlalu banyak megandung glukosa atau gula. Pengaturan pola makan lebih dibutuhkan bagi seseorang yang sudah memiliki faktor risiko yang tidak dapat diubah seperti mendekati 40 tahun dan ada riwayat keturunan diabetes.

\section{Aktivitas Fisik}

Berdasarkan hasil dari pengumpulan data diketahui bahwa aktivitas fisik dengan kategori kurang baik sebanyak 19 responden $(50 \%)$ sedangkan kategori baik sebanyak 19 responden $(50 \%)$.

Latihan jasmani merupakan salah satu pilar dalam pengelolaan DMT2 apabila tidak disertai adanya nefropati. Kegiatan jasmani sehari-hari dan latihan jasmani dilakukan secara secara teratur sebanyak 3-5 kali perminggu selama sekitar 30-45 menit, dengan total 150 menit perminggu. Jeda antar latihan tidak lebih dari 2 hari berturut-turut (Buss, \& Labus, 2013).

Sejalan dengan penelitian sebelumnya diketahui bahwa dari 17 responden pada kelompokkasus responden yang tidak olahraga sebanyak 14 orang $(82,4 \%)$ dan responden yang menjalankan olahraga sebanyak $3(17,6 \%)$ orang (Suryani, \& Septiana, 2016).

Berdasarkan hal tersebut peneliti berpendapat bahwa Olahraga dapat mengontrol gula darah, glukosa akan di ubah menjadi energi pada saat olahraga. Olahraga mengakibatkan insulin semakin meningkat sehingga kadar gula dalam darah akan berkurang. Pada orang yang jarang berolahraga, zat makanan yang masuk ke dalam tubuh tidak dibakar tetapi di timbun dalam tubuh sebagai lemak dan gula, jika insulin tidak mencukupi untuk mengubah glukosa menjadi energi maka akan timbul penyakit DM olahraga juga sangat berperan pada kontrol gula darah otot yang berkontraksi atau aktif tidak kurang memerlukan insulin untuk memasukan glukosa ke dalam sel, karena pada otot yang aktif lebih sensitif terhadap insulin, sehingga kadar gula darah menjadi turun.

\section{Hubungan pemantauan kadar gula darah dengan kejadian ulkus diabetikum}

Hasil uji statistik $p$ value $=0,006$ lebih kecil dari nilai alpha $(\alpha=0,05)$, sehingga ada hubungan pemantauan kadar gula darah dengan kejadian ulkus diabetikum. Hasil analisis diperoleh nilai OR: 9,500 atau dapat dikatakan pemantauan kadar gula darah yang tidak rutin berisiko 9,500 kali lebih besar terjadinya ulkus diabetikum pada pasien diabetes melitus tipe 2 dibandingkan dengan pemantauan kadar gula darah yang rutin.

Pemeriksaan gula darah mengidentifikasi diabetes melitus pada seseorang adalah dengan pemeriksaan kadar glukosa darah dan tidak dapat ditegakkan hanya atas dasar adanya glukosuria saja. Pemeriksaan glukosa dengan cara enzimatik dengan bahan darah plasma vena, seyogyanya dilakukan di laboratorium klinik terpercaya, tetapi sesuai dengan kondisi setempat dapat juga dipakai bahan darah utuh, vena, ataupun kapiler dengan memperhatikan angka-angka kriteria diagnostik yang berbeda sesuai pembakuan oleh WHO. Pemeriksaan penyaring dapat dilakukan melalui pemeriksaan kadar glukosa darah puasa, kemudian dapat diikuti dengan tes toleransi glukosa oral (TTGO) standar (Setiati, et all., 2014).

Penelitian ini didukung oleh penelitian sebelumnya menunjukkan hasil uji Chi-square memiliki hubungan antara gula darah hubungan dengan kejadian gangren pada pasien DM $(O R=$ 11.000 , nilai $P$ 0,024) (Wahyuni, Hasneli, \& Ernawaty, 2018).

Diketahui bahwa dari 15 responden dengan kategori pemantauan kadar gula darah tidak rutin dan tidak ada ulkus diabetikum sebanyak 5 responden $(33,3 \%)$. Hal ini dikarenakan responden tersebut selalu menjaga kaki dalam keadaan bersih, tidak basah, dan mengoleskan krim pelembab pada kulit kaki yang kering (hasil wawancara). Sedangkan dari 23 responden dengan kategori pemantauan kadar gula darah rutin dan terjadi ulkus diabetikum sebanyak 4 responden $(17,4 \%)$. Hal ini dikarenakan responden tersebut sering berjalan tanpa alas kaki dan kepatuhan diet yang kurang baik sehingga kadar gula darah tidak terkendali dan menyebabkan komplikasi

Berdasarkan hal tersebut peneltii berpendapat bahwa pemahaman pasien akan kondisinya sangat penting karena tingkat glukosa darah terus berubah. Seorang pasien harus memiliki pengetahuan yang cukup tentang penyakitnya sehingga mampu menjaga gula darah dalam batasan normal sehingga dapat mencegah terjadinya komplikasi diabetes. Beberapa hal yang dapat membantu pasien untuk menghindari masalah komplikasi tersebut adalah pendidikan,

Eka Yudha Chrisanto"* Program Studi Diploma IIl Keperawatan Universitas Malahayati.

*Email: yudhachrisanto88@gmail.com

Agustama ${ }^{2}$ Rumah Sakit Natar Medika Kabupaten Lampung Selatan 
dukungan diet, pola hidup sehat dan pemantauan glukosa darah secara ketat

\section{Hubungan kepatuhan diet diabetes dengan kejadian ulkus diabetikum}

Hasil uji statistik $p$ value $=0,002$ lebih kecil dari nilai alpha $(\alpha=0,05)$, sehingga ada hubungan kepatuhan diet diabetes dengan kejadian ulkus diabetikum. Hasil analisis diperoleh nilai OR: 13,933 atau dapat dikatakan kepatuhan diet diabetes yang tidak patuh berisiko 13,933 kali lebih besar terjadinya ulkus diabetikum pada pasien diabetes melitus tipe 2 dibandingkan dengan kepatuhan diet diabetes dengan kategori patuh.

Terapi Nutrisi Medis (TNM) merupakan bagian penting dari penatalaksanaan DMT2 secara komprehensif. Kunci keberhasilannya adalah keterlibatan secara menyeluruh dari anggota tim (dokter, ahli gizi, petugas kesehatan yang lain serta pasien dan keluarganya). Guna mencapai sasaran terapi TNM sebaiknya diberikan sesuai dengan kebutuhan setiap penyandang DM. Prinsip pengaturan makan pada penyandang DM hampir sama dengan anjuran makan untuk masyarakat umum, yaitu makanan yang seimbang dan sesuai dengan kebutuhan kalori dan zat gizi masingmasing individu. Penyandang DM perlu diberikan penekanan mengenai pentingnya keteraturan jadwal makan, jenis dan jumlah kandungan kalori, terutama pada mereka yang menggunakan obat yang meningkatkan sekresi insulin atau terapi insulin itu sendiri (Tandra, (2017).

Hal ini sejalan dengan penelitian lain bahwa diet merupakan salah satu upaya pengendalian kadar gula darah pada pasien DM tipe $2(\mathrm{p}=0,001)$ OR: 29,333 (Suryani, \& Septiana, 2016).

Diketahui bahwa dari 16 responden dengan kategori kepatuhan diet diabetes tidak patuh dan tidak ada ulkus diabetikum sebanyak 5 responden $(31,2 \%)$. Hal ini dikarenakan responden tersebut rutin melakukan pemeriksaan ke pelayanan kesehatan serta responden rutin mengikuti kegiatan senam di Puskesmas serta menjaga kebersihan kaki. Sedangkan dari 22 responden dengan kategori kepatuhan diet diabetes kategori patuh dan terjadi ulkus diabetikum sebanyak 3 responden $(13,6 \%)$ Hal ini dikarenakan responden tersebut jarang melakukan pemeriksaan gula darah. Meskipun responden patuh dalam hal diit tetapi responden kurang memperhatikan kebersihan kaki, dan jarang menggunakan alas kaki saat berjalan diluar rumah

Faktor yang sangat mempengaruhi kejadian ulkus diabetikum adalah pola makan dan pola hidup yang buruk. Pola makan yang buruk diantaranya makan makanan yang banyak mengandung lemak dan kalori tingi. Adapun pola hidup jelek adalah pola hidup yang tidak teratur dan penuh tekanan kejiwaan sepertis stres yang berkepanjangan (Niven, 2012).

\section{Hubungan aktivitas fisik dengan kejadian ulkus diabetikum}

Hasil uji statistik $p$ value $=0,002$ lebih kecil dari nilai alpha $(\alpha=0,05)$, sehingga ada hubungan aktivitas fisik dengan kejadian ulkus diabetikum. Hasil analisis diperoleh nilai OR: 14,571 atau dapat dikatakan aktivitas fisik yang kurang baik berisiko 14,571 kali lebih besar terjadinya ulkus diabetikum pada pasien diabetes melitus tipe 2 dibandingkan dengan aktivitas fisik yang baik.

Kegiatan sehari-hari atau aktivitas sehari-hari bukan termasuk dalam latihan jasmani meskipun dianjurkan untuk selalu aktif setiap hari. Latihan jasmani selain untuk menjaga kebugaran juga dapat menurunkan berat badan dan memperbaiki sensitivitas insulin, sehingga akan memperbaiki kendali glukosa darah. Latihan jasmani yang dianjurkan berupa latihan jasmani yang bersifat aerobik dengan intensitas sedang (50-70\% denyut jantung maksimal) seperti: jalan cepat, bersepeda santai, jogging, dan berenang. Denyut jantung maksimal dihitung dengan cara mengurangi angka 220 dengan usia pasien (Nabila, 2019).

Sejalan dengan hasil penelitian lain bahwa olahraga merupakan faktor resiko terhadap pengendalian kadar gula darah pada pasien DM tipe 2 dengan nilai ( $p=0,000)$ OR: 35,000 (Suryani, \& Septiana, 2016).

Diketahui bahwa dari 16 responden dengan Kategori aktivitas fisik kurang baik dan tidak ada ulkus diabetikum sebanyak 7 responden $(36,8 \%)$. Hal ini dikarenakan responden tersebut rutin melakukan pemeriksaan gula darah serta kepatuhan pola makan yang baik. Selain itu responden juga minum obat secara teratur. Sedangkan dari 19 responden dengan kategori aktivitas fisik baik dan terjadi ulkus diabetikum sebanyak 2 responden (10,5\%) Hal ini dikarenakan responden tersebut sering beraktivitas diluar rumah seperti berkebun dan responden tidak

Eka Yudha Chrisanto* Program Studi Diploma IIl Keperawatan Universitas Malahayati.

*Email: yudhachrisanto88@gmail.com

Agustama ${ }^{2}$ Rumah Sakit Natar Medika Kabupaten Lampung Selatan 
menjaga kebersihan kaki, dari hasil wawancara juga diketahui responden tersebut jarang melakukan pemeriksaan gula darah

Menurut pendapat peneliti bahwa kegiatan fisik dan olah raga bermanfaat bagi setiap orang karena dapat meningkatkan kebugaran, mencegah kelebihan berat badan, meningkatkan fungsi jantung, paru, otot-otot serta memperlambat proses penuaan. Dengan demikian olahraga juga akan bermanfaat untuk mencegah terjadinya serangan penyakit diabetes. Olahraga yang disarankan adalah yang bersifat aerobik. Jenis olahraga aerobik diantaranya adalah jalan cepat, bersepeda, joging dan renang dianjurkan olahraga 30-45 menit sehari dengan frekuensi 4-5 kali per minggu.

\section{SIMPULAN}

Hasil uji chi square menunjukan ada hubungan pemantauan kadar gula darah dengan kejadian ulkus diabetikum pada pasien diabetes melitus tipe 2. Hasil uji statistik $p$ value $=0,006(\alpha=0,05)$ OR: 9,500. Ada hubungan kepatuhan diet diabetes dengan kejadian ulkus diabetikum pada pasien diabetes melitus tipe 2. Hasil uji statistik $p$ value $=$ 0,002 ( $\alpha=0,05)$ OR: 13,933.Ada hubungan aktivitas fisik dengan kejadian ulkus diabetikum pada pasien diabetes melitus tipe 2. Hasil uji statistik $p$ value $=0,002(\alpha=0,05)$ OR: 14,571.

\section{SARAN}

Diharapkan bagi pelayanan keperawatan dapat melaksanakan kegiatan pendidikan kesehatan yang direncankan dan berkseinambungan yang ditujukan bagi pasien maupun keluarga khususnya perawatan kaki diabetikum, Diet DM, Aktifitas Maupun latihan dan juga melakukan pemeriksaan kaki melalui visual inspection untuk mendeteksi adanya faktot resiko terjadinya ulkus diabetikum. Bagi Rumah sakit agar dapat disediakan ruangan agar pasien dapat berkonsultasi mengenai perawatan keseatan secara mandiri. Bagi pasien DM agar rutin melakukan aktivitas fisik serta rutin mengontrol kadar gula darah pada fasilitas pelayanan kesehatan serta memanfaatkan pelayanan kesehatan seperti mendiskusikan dengan petugas kesehatan jika mengalami hambatan dalam melakukan aktivitas fisik.

\section{DAFTAR PUSTAKA}

American Diabetes Association. (2016). Standards of medical care in diabetes-2016 abridged for primary care providers. Clinical diabetes: a publication of the American Diabetes Association, 34(1), 3.

Arisman, M. B. (2011). Buku Ajar Ilmu Gizi Obesitas, Diabetes Melitus \& Dislipidemia: Konsep, Teori dan Penanganan Aplikatif. Jakarta: EGC.

Aspiani, R. Y. (2014). Buku Ajar Asuhan Keperawatan Gerontik. Jakarta: Trans Info Media.

Buss, J. S., \& Labus, D. (2013). Buku saku patofisiologi. Jakarta: EGC.

Fathmi, A. (2012). Hubungan Indeks Massa Tubuh dengan Kadar Gula Darah pada Penderita Diabetes Melitus Tipe 2 di Rumah Sakit Umum Daerah Karanganyar (Doctoral dissertation, Universitas Muhammadiyah Surakarta).

Kartika, R. W. (2017). Pengelolaan gangren kaki diabetik. Continuing medical education, 44(1), 18-21.

Kementerian Kesehatan Republik Indonesia. (2017). Profil kesehatan Indonesia tahun 2016. Diakses dari https://www.kemkes.go.id/resources/download/ pusdatin/profil-kesehatan-indonesia/ProfilKesehatan-Indonesia-tahun-2017.pdf

Lingga, L. (2012). Bebas diabetes tipe-2 tanpa obat. AgroMedia.

Nabila, A. (2019). Gambaran Senam Jantung Sehat Dan Kualitas Hidup Pasien Hipertensi Yang Mengikuti Program Pengelolaan Penyakit Kronis (Prolanis) Di Wilayah Kerja Puskesmas Dau Kabupaten Malang (Doctoral dissertation, University of Muhammadiyah Malang).

Niven, N. (2012). Psikologi Kesehatan: Pengantar untuk perawat dan tenaga kesehatan profesional lain. Jakarta: EGC.

\footnotetext{
Eka Yudha Chrisanto* Program Studi Diploma IIl Keperawatan Universitas Malahayati.

*Email: yudhachrisanto88@gmail.com

Agustama ${ }^{2}$ Rumah Sakit Natar Medika Kabupaten Lampung Selatan
} 
Notoatmodjo, S. (2014). IImu Perilaku Kesehatan. Jakarta: Rineka Cipta.

Perkumpulan Endokrinologi Indonesia. (2015). Konsensus Pengelolaan Dan Pencegahan Diabetes Melitus Tipe 2 Di Indonesia 2015. Jakarta: Pengurus Besar Perkumpulan Endokrinologi Indonesia (PB PERKENI).

Rachmawati, N., \& Kusumaningrum, N. S. D. (2017). Gambaran Kontrol dan Kadar Gula Darah pada Pasien Diabetes Melitus di Poliklinik Penyakit Dalam RSJ Prof. Dr. Soerojo Magelang (Doctoral dissertation, Universitas Diponegoro).

Rahayu, K. B., Saraswati, L. D., \& Setyawan, H. (2018). Faktor-Faktor yang Berhubungan dengan Kadar Gula Darah pada Penderita Diabetes Melitus Tipe 2 (Studi di Wilayah Kerja Puskesmas Kedungmundu Kota Semarang. Jurnal Kesehatan Masyarakat (eJournal), 6(2), 19-28.

Ranti, I., Rumagit, F., \& Montol, A. (2013). Aktivitas Fisik dan Total Asupan Lemak Terhadap Komponen Sindrom Metabolik pada Pegawai dan Staf Politeknik Kesehatan Manado. Jurnal Gizido, 5(2), 127-139.
Setiati, S., Alwi, I., Sudoyo, A. W., Simadibrata, M., Setiyohadi, B., \& Syam, A. F. (2014). Buku ajar ilmu penyakit dalam. Jakarta: Interna Publishing.

Suryani, N., \& Septiana, H. (2016). Diet dan Olahraga sebagai Upaya Pengendalian Kadar Gula Darah pada Pasien Diabetes Melitus Tipe 2 di Poliklinik Penyakit Dalam RSUD Ulin Banjarmasin Tahun 2015. Jurnal Kesehatan Indonesia, 6(2).

Tandra, H. (2017). Segala sesuatu yang harus anda ketahui tentang diabetes. Gramedia Pustaka Utama.

Wahyuni, S., Hasneli, Y., \& Ernawaty, J. (2018). Hubungan Kadar Gula Darah Dengan Terjadinya Gangren Pada Pasien Diabetes Mellitus. Jurnal Keperawatan 3 (3). Universitas Riau.

Yunus, B. (2015). Faktor-faktor yang Mempengaruhi Lama Penyembuhan Luka pada Pasien ULKUS Diabetikum di Rumah Perawatan ETN Centre Makassar (Doctoral dissertation, UIN Alauddin Makassar). 